DOI: 10.12957/demetra.2016.23426

\title{
Gênero e formação profissional: considerações acerca do papel feminino na construção da carreira de nutricionista
}

\section{Gender and profession: considerations on female roles in building the nutritionist career}

Liv Katyuska de Carvalho Sampaio de

Souza'

Flávia Milagres Campos

Fabiana Bom Kraemer

Paula Aballo Nunes Machado 1,2

Maria Claudia Veiga Soares Carvalho, ${ }^{1,3}$

Shirley Donizete Prado

\footnotetext{
1 Universidade do Estado do Rio de Janeiro, Instituto de Nutrição, Programa de PósGraduação em Alimentação, Nutrição e Saúde, Núcleo de Estudos sobre Cultura e Alimentação (NECTAR). Rio de Janeiro-RJ, Brasil.

2 Universidade Estácio de Sá. Rio de Janeiro-RJ, Brasil.

${ }^{3}$ Universidade Federal do Rio de Janeiro, Instituto de Nutrição Josué de Castro. Rio de Janeiro-RJ, Brasil.

Correspondência / Correspondence Liv Katyuska de Carvalho Sampaio de Souza E-mail: livkatyuska@hotmail.com
}

\section{Resumo}

A trajetória coletiva traçada pela Nutrição manifesta-se no fato de que ela se naturaliza como uma profissão feminina e nos remete às discussões sobre a distinção entre gêneros tal como a concebemos contemporaneamente. A partir de uma concepção de gênero como uma construção histórica e cultural, e não da natureza, propomos uma reflexão acerca da formação profissional centrada na questão do gênero como categoria analítica. Acenamos para a articulação entre o trabalho profissional e o trabalho doméstico, confundindo a esfera privada com a pública, o que pode ter contribuído para a dificuldade inicial de se traçar a identidade profissional do nutricionista. Apontamos, ainda, para a articulação entre nutrição e gênero, também fruto de um habitus que naturaliza a profissão do nutricionista como feminina.

Palavras-chave: Nutrição. Gênero. Profissões.

\section{Abstract}

The collective trajectory traced by Nutrition is manifested in the fact that it is naturalized as a female profession and arises the discussion on the distinction between genders as conceived contemporaneously. From a gender conception as a historical and cultural construction, we propose a reflection of professional qualification focused on gender as an analytic category. We indicated the relationship between the professional and the household works confusing the private space with the public, which may have contributed to the initial difficulty in outlining 
the professional nutritionist identity. Likewise, we pointed to links between nutrition and gender, also as result of a habitus that naturalizes the profession of nutritionist as feminine.

Key words: Nutrition. Gender Identity. Occupations.

\section{Introdução}

A Nutrição faz parte do conjunto de profissões ditas como "femininas" no Brasil. O Conselho Federal de Nutricionistas, ${ }^{1}$ ao buscar um retrato ampliado do nutricionista no país, no que diz respeito às características sociodemográficas, formação, exercício profissional, entre outros, identificou que 96,5\% eram mulheres. Esta presença marcante vem de sua aproximação com a primeira profissão feminina universitária - a enfermagem, fortemente atrelada à necessidade social do cuidar.

Os cuidados com a alimentação inseriam-se entre outras funções da enfermeira consideradas indispensáveis ao bem-estar do paciente. Contudo, é preciso registrar que o movimento de industrialização brasileiro e a emergência dos conhecimentos sobre nutrição, nas décadas de 1930 e 1940, são indicados na literatura como parte importante do cenário de constituição da profissão de nutricionista., ${ }^{2,3}$ Esse movimento vai ao encontro das mudanças observadas no cenário global a partir da Segunda Grande Guerra. Observa-se um momento de redistribuição da mão de obra feminina no mercado de trabalho, inserindo-se em atividades antes ocupadas apenas por homens, como por exemplo, a engenharia. ${ }^{4}$

Os primeiros cursos de Nutrição no Brasil, inclusive, datam desse período, com a criação dos cursos técnicos de nível médio para formação de nutricionistas-dietistas. O Serviço de Alimentação da Previdência Social (SAPS), ${ }^{a}$ que tinha como função garantir refeições dignas e baratas à emergente mão de obra industrial por meio de restaurantes populares, tornou-se um dos principais centros de formação de nutricionistas e também um importante campo de trabalho, pois as "moças" que concluíam o curso tinham a possibilidade de ingressar no quadro de funcionários permanentes da autarquia, destacando a hegemonia feminina desde o surgimento da profissão. ${ }^{7}$

O reconhecimento da profissão como nível superior se deu apenas em 1962, pelo Ministério da Educação. Nesse processo, destaca-se o papel da Associação Brasileira de Nutrição, criada

a O Serviço de Alimentação da Previdência Social (SAPS) originou-se em 1940, na cidade do Rio de Janeiro, então Capital da República, com posterior expansão para outras cidades. Eram restaurantes tecnicamente dirigidos aos segurados dos Institutos e Caixas de Aposentadoria e Pensões, subordinados ao Ministério do Trabalho, Indústria e Comércio, sob a responsabilidade de médicos e dietistas, que serviam um cardápio fixo considerado cientificamente balanceado em sua composição química. ${ }^{5,6}$ 
em 1949, sendo a primeira entidade brasileira a representar e a defender os interesses dos nutricionistas/dietistas. ${ }^{8}$

Estudos sobre a profissão, como o de Vasconcelos \& Calado, ${ }^{8}$ fazem menção à predominância de mulheres desde aquela época e citam o primeiro boletim dessa associação, publicado em 1959, que descreve a formação como sendo de grande utilidade, em especial para as mulheres, pois "dotaria para o cuidado com a saúde da família e o controle da economia doméstica". 9

A história da profissão é, assim, marcada por sua criação em um contexto de transformações econômicas, políticas e sociais, associado ao período nacional designado como Estado Novo (19371945), em que o então presidente, Getúlio Vargas, com apoio das Forças Armadas, se manteve no poder sob a justificativa de conter uma nova ameaça de golpe comunista no Brasil. Além de toda discussão em torno do modelo político adotado à época, um ponto marcante do governo nesse período foi a orientação populista notada entre a relação governo e classes trabalhadoras, fundamentais para o crescimento da burguesia industrial. O Estado, assim, aprofundou investimentos no setor industrial brasileiro em substituições de importações, sobretudo na metalurgia e siderurgia. Com um patamar mais prestigiado na economia, importantes mudanças na estrutura da sociedade ocorreram, criando oportunidade para a inserção da mulher no espaço do trabalho, como a intensificação do fluxo migratório do campo para os centros urbanos, proporcionando maior oferta de mão de obra.

A mulher, nesse período, vai ocupando espaços, tendo maior participação no mercado de trabalho e em outros setores, como no rádio e cinema. No entanto, não devemos esquecer, como argumenta Nahes, ${ }^{10}$ a visão que ainda existia em relação à mulher, da mãe e esposa perfeita - imagem controversa à mulher trabalhadora, politizada, militante e que ocupava um espaço público nas décadas de 1910 e 1920. Assim, o Ministro da Educação entre 1937 e 1945, Gustavo Capanema afirmou:

[...] reservava às mulheres um tratamento especial e que, durante o Estado Novo, se desdobraria em dois segmentos similares: de um lado, proteção à família, quando a colocava sob a proteção do Estado; de outro, deveria ser dada à mulher uma "educação adequada" ao seu papel familiar, ou seja, adequada ao Estado, evidentemente. ${ }^{10}$

É plausível afirmar que a formação em Nutrição, nessa época, atendia a essa proposta, mas foi se modificando ao longo do tempo. Da década de 1940 até os dias atuais, os cursos de Nutrição do país cresceram vertiginosamente, entre 1939 e 2009 foram criados $391 .^{8}$ Atualmente, são 431 cursos autorizados, 81.745 nutricionistas formados e 11.427 técnicos em nutrição. ${ }^{11} \mathrm{E}$, de acordo com os dados divulgados pelo Instituto Nacional de Estudos e Pesquisas Educacionais Anísio Teixeira (INEP), verifica-se que o predomínio de mulheres persiste até os dias atuais: dentre os concluintes dos cursos de graduação em Nutrição, 93,4\% são do sexo feminino. ${ }^{12}$ 
Paralelamente a este crescimento, observam-se o aperfeiçoamento dos instrumentos de trabalho, transformações no mercado e condições de trabalho desses profissionais ${ }^{8}$ e mudanças na orientação do perfil profissional. Segundo as Diretrizes Curriculares Nacionais do Curso de Graduação em Nutrição, o perfil profissional é: ${ }^{3}$

Nutricionista, com formação generalista, humanista e crítica, capacitado a atuar, visando à segurança alimentar e à atenção dietética, em todas as áreas do conhecimento em que alimentação e nutrição se apresentem fundamentais para a promoção, manutenção e recuperação da saúde e para a prevenção de doenças de indivíduos ou grupos populacionais, contribuindo para a melhoria da qualidade de vida, pautado em princípios éticos, com reflexão sobre a realidade econômica, política, social e cultural; [...]

A trajetória coletiva traçada pela Nutrição, por meio de um processo de socialização em que são organizados e tipificados papéis sociais, manifesta-se no fato de que ela se naturaliza como uma profissão feminina e nos remete às discussões sobre a distinção entre gêneros tal como a concebemos contemporaneamente.

A diferença biológica entre os sexos é assumida segundo a hierarquia social, associando características tidas como naturais das mulheres às atividades relacionadas ao trabalho doméstico, envolvendo o cuidado e a expressão de afeto, enquanto os homens vinculam-se à esfera do trabalho e à vida social nas ruas e ocupam espaços de poder político, justificando as desigualdades entre homens e mulheres. Assim, a diferenciação biológica é usada como justificativa para a suposta incapacidade das mulheres para atuarem no mercado de trabalho ou para atuarem em determinadas profissões. ${ }^{14}$ Dessa forma, carreiras profissionais tradicionalmente consideradas de maior prestígio, como Medicina, Direito e Engenharia, eram majoritariamente ocupadas por homens e este quadro começa a se alterar mais intensamente apenas a partir da década de $1990 .{ }^{15}$ Contudo, ainda que atualmente as mulheres ocupem postos de trabalho em profissões que até alguns anos atrás eram dominadas por homens, assimetrias persistem. Podemos tomar como exemplo as desigualdades, especialmente nos postos de comando, quando se comparam salários de homens e mulheres. ${ }^{16,17}$ Por outro lado, homens que optam por profissões historicamente construídas como femininas, como Enfermagem, Educação Infantil ou mesmo Nutrição, assumem uma posição díspar, frente ao estereótipo estabelecido. Essas nuanças nos ajudam a perceber que é no jogo social que se definem os papéis, naturalizando as escolhas como se fossem aptidões de cada sexo.

Assim, algumas mudanças nas representações sobre o papel feminino no âmbito familiar e no mundo do trabalho nos remetem a importantes reflexões no campo das profissões. Pensar a formação do nutricionista, em nossa perspectiva, extrapola os estudos sobre o conhecimento técnico e científico, e a necessidade de ampliação de habilidades e competências para atuar no mundo do trabalho. Refletir sobre as atividades de classificação hierarquizada entre homens e mulheres e 
seus respectivos atributos, bem como a influência nas escolhas de carreira dos indivíduos, parecenos uma importante questão pouco debatida na Nutrição.

Objetivamos, assim, apresentar e discutir a questão da natureza feminina na Nutrição enquanto profissão. Assumindo o formato de ensaio, neste texto não buscamos dar respostas, mas a partir de reflexões sobre a história da profissão, procuramos vislumbrar questões pertinentes ao presente e futuro da profissão.

\section{Gênero e nutrição}

O conceito de gênero tem sido debatido e apropriado por diversas disciplinas, como Filosofia, Psicologia, Sociologia e Antropologia. Não iremos discutir as várias abordagens feitas ao tema. O que é de nosso interesse e que fundamenta nossa reflexão aqui é pensar gênero como uma construção histórica e cultural e não da natureza. Assim, o conceito se apresenta de forma plural, ou seja, feminino, masculino ou transgênero são construídos de formas diversas no interior da sociedade e da cultura, na medida em que os papéis sexuais são estabelecidos pela sociedade, inclusive direcionando a escolha profissional.

[...] não há uma representação "correta" da mulher em relação ao homem e que toda ciência da diferença

é, portanto, mal interpretada. É bem verdade que há e houve uma considerável e frequente tendência misógina em grande parte da pesquisa biológica sobre as mulheres; a história trabalhou claramente para "racionalizar e legitimar" as distinções, não só de sexo, mas também de raça e classe, com desvantagem para os destituídos de poder. ${ }^{18}$

Sob essa perspectiva, naturalizam-se profissões desempenhadas por homens e mulheres na sociedade, sendo conferidas às mulheres atividades do seio privado de educação dos filhos e do cuidado com a vida, das relações interpessoais e de expressões do afeto; e aos homens, tarefas da esfera pública com características relacionadas à racionalidade e competitividade, à conquista, ao perigo físico, à dominação e ao exercício do poder sobre outros. ${ }^{19,20}$ Apesar de a polarização "feminino e masculino" ser mais evidente no presente ensaio, não podemos deixar de sinalizar a diversidade de gênero no que se refere à formação profissional e de carreira. Destacamos, assim, alguns eventos noticiados na imprensa, como o aumento no número de transgêneros inscritas no Exame Nacional do Ensino Médio (ENEM), o reconhecimento do uso do nome social em algumas universidades públicas brasileiras e a possibilidade de uma transgênero se tornar reitora de uma universidade. ${ }^{21,22}$

Na Nutrição, as discussões acerca da formação profissional, até o momento, não estão centradas na questão do gênero. Costa $^{23}$ relata a formação do nutricionista a partir de uma retrospectiva 
histórica dos eventos e estudos brasileiros e latino-americanos que ocorreram até aquele momento. A autora descreve que, a partir da década de 1970, quando houve aumento nos cursos de Nutrição latino-americanos, a discussão, inicialmente em eventos científicos na América Latina, se fazia em torno da identidade profissional. Parece que não estava clara, à época, a necessidade de instituir essa carreira e seu objeto de prática. Havia um empenho, nesses fóruns, de ressaltar a importância do nutricionista e esclarecer as atribuições e funções do profissional em busca de um delineamento claro. Recomendações foram elaboradas para a realização de estudos sobre o tema e, no ensino, para orientar a formação como requisitos mínimos para admissão no curso, duração, qualificação docente, aspectos considerados essenciais para a organização dos programas de ensino, entre outros.

Nas décadas que se seguiram, 1980, 1990 e 2000, continuou a reflexão sobre o perfil profissional e intensificaram-se as discussões, na tentativa de delimitar as atribuições do nutricionista e os contornos da formação acadêmica, bem como buscar soluções para os problemas identificados na formação do nutricionista. Na década de 1980, destaca-se a discussão da inter-relação com outras profissões no contexto mais abrangente dos profissionais da área de saúde e seu compromisso com a maioria da população brasileira - no caso, as necessidades nutricionais. ${ }^{23}$ Segundo a autora, a preocupação central na especificidade das competências do nutricionista e na análise da situação da formação estava relacionada a uma baixa visibilidade social da profissão, que carecia de uma identidade própria tanto para a sociedade quanto para a própria categoria.

No bojo das discussões sobre perfil e competências profissionais, citamos Maria Lúcia Magalhães Bosi, ${ }^{24}$ que publicou o livro Profissionalização e conhecimento: a nutrição em questão, em 1996, onde discutiu a identidade e a profissionalização do nutricionista. Para a autora, todo debate sobre a falta de clareza para a categoria do objeto de sua prática, suas funções, atribuições e compromissos tocava na própria identidade da categoria, em sua relação com o grau de profissionalização pela prática que desenvolvia - ou seja, na própria razão de ser da "profissão"b como um todo.

[...] o que se nota é uma luta em defesa de um objeto, a busca de uma identidade que defina e confira autonomia à categoria. Esse objeto que, sob vários nomes, apresenta-se exclusivo e legítimo para os nutricionistas, tem sua defesa calcada no argumento de uma pretensa especificidade no nível da formação, o que, entretanto, não resiste ao confronto com a prática. ${ }^{24}$

A menção do trabalho da autora se justifica pelo esforço que ela empregou para elucidar as circunstâncias em que os nutricionistas desenvolviam esforços para sua profissionalização através de uma reflexão sobre os impasses e possibilidades da categoria. Para tanto, se deteve na questão

b O termo "profissão" é utilizado entre aspas pela autora, pois parte da hipótese de que a Nutrição era uma semiprofissão, pois não possuía uma base cognitiva que lhe possibilitasse uma clara identidade profissional e reivindicava uma jurisdição exclusiva sobre determinada área de saber e prática. 
da análise da dimensão cognitiva e evidenciou que a graduação em Nutrição não instrumentalizava suficientemente os nutricionistas para exercício de uma prática autônoma e claramente definida e a reivindicação de uma jurisdição exclusiva sobre determinada área de saber e prática. Em sua contribuição para a construção de um perfil do nutricionista brasileiro, discutiu a questão do gênero, pois considerou um ponto importante para o estudo sobre profissionalização.

Nesse ponto, fez uma breve discussão sobre um menor prestígio para quem exerce a carreira e o processo de inserção tardia e marginal da mulher ao trabalho produtivo. Em parte, explicou que essa desvalorização, inclusive em termos monetários, está relacionada ao fato de as "profissões femininas" desempenharem na esfera pública atividades equivalentes às que as mulheres desempenhavam no espaço privado. Para exemplificar, citou as palavras de uma das pioneiras na formação do nutricionista: "O curso básico de Nutrição [...] enquadra-se dentro de suas afinidades naturais femininas, sendo a profissão, sob muitos aspectos, uma dilatação de suas atribuições domésticas". ${ }^{24}$ Bosi $^{24}$ apresentou que a visão tradicional da divisão sexual de tarefas, que obriga as mulheres a buscarem conciliar as atividades domésticas, como cuidar dos filhos, e as da vida profissional, é um obstáculo imposto à ascensão profissional na competição com o sexo masculino. O enfoque no gênero também foi considerado um fator que influenciava na escolha da profissão, na medida em que o papel desempenhado pela mulher na esfera social da vida privada se reproduz na escolha da profissão, pois se vincula às relações de dominação masculina na família. A tradição cultural, a organização e a estrutura do mercado de trabalho também modelam o trabalho profissional, ao restringirem o ingresso delas em outros setores, como a opção por vínculos que lhes permitam a adequação de horários e atividades relativas ao âmbito familiar.

Outros estudos foram realizados na busca do detalhamento da prática profissional e suas relações. Andrade \& Lima, ${ }^{9}$ por exemplo, ao considerarem a questão do gênero como um aspecto importante para a configuração da identidade e a autonomia no processo de profissionalização, analisaram em que medida a categoria "gênero" constituiu objeto de pesquisa no campo da Alimentação e Nutrição entre o período de 1980 a 2002.

As autoras constataram que, no conjunto das pesquisas, o "gênero" não constituiu uma categoria analítica central e as discussões perpassavam as argumentações muito mais pela constatação da hegemonia feminina na profissão e da dificuldade encontrada pela mulher no mundo do trabalho, neste último, expressas principalmente pela postura de conformação diante das situações adversas inerentes ao trabalho.

Podemos presumir que a inexpressiva abordagem sobre gênero nos estudos sobre formação e práticas profissionais em Nutrição relaciona-se também ao fato de que a perspectiva de gênero, como categoria analítica, se desenvolveu sobretudo a partir da década de 1980. Além disso, a consolidação do campo científico em Alimentação e Nutrição é recente e tem seus objetos de estudos centrados no "nutriente" e no "alimento"..$^{25}$ 
Não encontramos recentes estudos que se debrucem sobre uma análise entre nutrição e gênero. Olhamos, no entanto, para a história da formação profissional e fazemos algumas considerações.

Dentre os primeiros cursos de formação em Nutrição, aqueles oferecidos pelo SAPS, inicialmente para formação de auxiliares ou visitadoras de alimentação, eram destinados exclusivamente a mulheres. ${ }^{26,27}$ Podemos afirmar, assim como Bourdieu, ${ }^{14}$ que ao direcionar os cursos de Nutrição para as mulheres, o SAPS "consagra a ordem estabelecida, trazendo-a a existência conhecida e reconhecida, oficial". Nesse caso, a mulher sai do ambiente doméstico para trabalhar, mas parte de seu trabalho nos restaurantes é vista como uma extensão das tarefas domésticas. Embora trabalhe em condições diferentes no restaurante, ao fim e ao cabo, a mulher/nutricionista continua sendo a responsável pela alimentação.

Este direcionamento dos cursos às mulheres, como dito anteriormente, está relacionado à atribuição da formação profissional às funções reconhecidas como femininas. Ainda segundo Bourdieu, ${ }^{14}$ isso que o discurso imputa como característica natural da mulher, na verdade, está imerso nas condições sociais de sua possibilidade. Nesse caso, a capacidade de cozinhar entendida como uma afinidade feminina tem sua possibilidade produzida, por exemplo, na disponibilidade para aprender a cozinhar no ambiente familiar (essa era uma lição dada às meninas, e não aos meninos) ou no incentivo a cozinhar como uma brincadeira de meninas; ou ainda, como condição necessária à constituição de novas famílias e para que a mulher pudesse assumir seu papel de esposa (não nos esqueçamos do ditado popular "ela sabe cozinhar, agora já pode casar”). E ainda, o que para alguns autores colocava o nutricionista como mão de obra subalterna, subordinada à prática médica, ${ }^{23,24}$ para nós o fato de ser naturalizada como profissão feminina contribui para situá-la nesta condição.

Por outro lado, ao mesmo tempo em que se identifica a semelhança do trabalho doméstico e o trabalho nos restaurantes - a responsabilidade pela alimentação como tarefa essencialmente feminina - é preciso ressaltar que o deslocamento da responsabilidade da alimentação doméstica para a dos restaurantes também permitiu à mulher/nutricionista incorporar certo poder. Ao sair do trabalho informal em casa para um trabalho formal nos restaurantes, a mulher/nutricionista mudou sua posição, saindo da esfera exclusivamente doméstica e passando a compor também o mercado de trabalho e o próprio campo da Alimentação e Nutrição, ainda que dentro de certos limites.

Em vez de ser responsável somente pela casa e pelos filhos, passa a ser responsável também pelo funcionamento dos restaurantes e pelos funcionários incumbidos da tarefa de manipular os alimentos. Isso trouxe implicações para esse agente, ao conceder prestígio e poder relacionados ao novo saber que passou a deter: organizar a produção de refeições em grandes quantidades. 
Assim sendo, os depoimentos de nutricionistas que se formaram e trabalharam no SAPSc são bastante ilustrativos:

O trabalho desenvolvido foi uma coisa maravilhosa, porque eu nunca tinha tido um tipo de trabalho desse jeito. Comandar aquele grupo, um restaurante para mais de mil pessoas. Preparar aqueles cardápios! O nosso trabalho era orientar o pessoal, elaborar aqueles cardápios, todos de acordo com a técnica. Passar para a cozinha tudo aquilo [... $]^{28 d}$

[...] Além de estudar, eu ia ganhar um dinheirinho, que me permitiria comprar os livros, cadernos e não ser peso para meus pais. Diante disso, minha mãe e meu pai assentiram [...) no início eram fornecidas três mil refeições por dia, depois aumentamos, e chegamos a dez mil refeições por dia. A gente colocava a mão na massa para ensinar determinados pratos aos cozinheiros. (...) participávamos da administração fiscalizando a entrada de alimentos (...) tínhamos a responsabilidade da organização dos cardápios balanceados para evitar os excessos ou as carências. ${ }^{28}$ e

Dois pontos reconhecíveis nos depoimentos são a possibilidade de conquistar certa independência financeira ao ingressar no SAPS (tanto como profissional, como quanto estudante, já que eram concedidas bolsas de estudos para as "moças") e a possibilidade de instruir-se com um saber científico e legitimado, que garantia o exercício profissional em um espaço respeitável.

Do mesmo modo, à época, a extensão do trabalho doméstico à esfera profissional pode ter contribuído para a dificuldade inicial dos nutricionistas em traçarem uma identidade profissional, ${ }^{24}$ significando que a Nutrição, assim como as demais profissões ditas femininas, articula o trabalho profissional com o trabalho doméstico, confundindo a esfera privada com a pública, fazendo com que a mulher não distinga os limites entre as duas.

\section{A questão de gênero na pós-graduação}

As reflexões sobre gênero e nutrição também podem ser ampliadas à formação pós-graduada. No Brasil, a educação vem se destacando ao longo do tempo nos estudos de mobilidade social como determinante das trajetórias sociais. A remuneração média dos brasileiros eleva-se de maneira marcada quando ele passa de um nível educacional para o imediatamente superior. Os brasileiros

c Trata-se dos depoimentos de nutricionistas que se formaram no SAPS e ali trabalharam, contando como ingressaram no curso para nutricionista, bem como parte de suas experiências como estudantes e como profissionais.

d Depoimento de Oswaldina Nole do Nascimento, concedido a Ana Maria da Costa Evangelista, Rio de Janeiro, em abril de 2010.

e Depoimento de Euthalia de Araújo Tavares, concedido a Ana Maria da Costa Evangelista, Rio de Janeiro, em agosto de 2010 . 
cujo nível de instrução mais elevado é o mestrado recebem remuneração média 84\% superior aos que apenas concluíram o curso superior; e os que concluíram o doutorado recebem $35 \%$ mais do que os que só fizeram o mestrado. ${ }^{29}$

Tal mobilidade tem estimulado homens e mulheres a investirem na educação, estando as mulheres cada vez mais inseridas nas pós-graduações. Em 2009, as mulheres predominavam dentre os egressos de mestrado (homens 46,5\% e mulheres 53,5\%), não existindo, contudo, uma preponderância feminina em todas as grandes áreas do conhecimento. Destacavam-se de maneira muito acentuada nas áreas de Ciências da Saúde e de Linguística, Letras e Artes. As três áreas do conhecimento da área de Ciências da Saúde em que a presença feminina mais se destacou foram Fonoaudiologia (95,95\%), Enfermagem $(91,88 \%)$ e Nutrição $(88,13 \%)$. Nas grandes áreas de Engenharias e de Ciências Exatas e da Terra, as mulheres representavam menos de um terço do total de titulados nesse ano. ${ }^{29}$

No que tange ao doutorado, em 2008, havia praticamente uma igualdade entre homens e mulheres titulados, com um pequeno destaque das mulheres, mas mantendo o mesmo padrão do mestrado: a Área de Linguística, Letras e Artes era a de participação feminina mais elevada $(63,8 \%)$, e a mais baixa era a de Engenharias (33,3\%). A Grande Área de Ciências da Saúde, a que mais titula doutores, apresentava nesse ano em torno de $60 \%$ de mulheres dentre seus titulados, destacando-se com a presença feminina a Fonoaudiologia (100\%), Enfermagem (90,8\%), Saúde Coletiva $(69,4 \%)$ e Nutrição $(66 \%) .{ }^{30}$

Em estudo conduzido com mestres formados por dez programas de pós-graduação stricto sensu no Brasil na Área de Nutrição da Capes (em sua maioria nutricionistas do sexo feminino), a ascensão salarial, a maior autoconfiança e o reconhecimento pelos pares foram identificados como principais mudanças na vida profissional atribuídas ao título de mestrado por esses egressos. ${ }^{31}$

Bourdieu $^{32}$ nos fala da lógica da nomeação oficial, a qual nunca se vê tão bem como no caso do título - nobiliário, escolar, profissional -, capital simbólico, social e até mesmo juridicamente garantido. O nobre, segundo ele, não é somente aquele que é conhecido e célebre. Ele é também aquele que é reconhecido por uma instância oficial, "universal" - quer dizer, conhecido e reconhecido por todos. O título profissional ou escolar é uma espécie de regra jurídica de percepção social. É um capital simbólico institucionalizado, presente no discurso das nutricionistas do SAPS e dos mestres nutricionistas no estudo citado.

De uma forma geral, apesar de uma superação das mulheres no que se refere à conclusão do mestrado e proporções semelhantes no doutorado, isto ainda não se refletiu em maior proporção feminina no meio acadêmico. Temos ainda uma participação feminina mais baixa no corpo docente universitário e baixa presença de mulheres nos mais altos postos das hierarquias de ensino superior. Segundo o Censo de Educação Superior de $2013,{ }^{33}$ os homens representavam 54,9\% das funções docentes na educação superior no Brasil, enquanto as mulheres, 45,1\%. O perfil do docente de 
ensino superior é ter em torno de 35 anos, ser do sexo masculino e possuir o título de doutorado com dedicação exclusiva nas instituições de ensino superior (IES) públicas e de mestrado com regime de trabalho horista nas IES privadas.

Mais especificamente em relação ao corpo docente de pós-graduação stricto sensu, dados de 2003 apontam que as mulheres representavam apenas 36,1\% das funções docentes nesse nível educacional, sendo sua presença majoritária nas Grandes Áreas de Linguística, Letras e Artes $(60,7 \%)$ e de Ciências Humanas (50,6\%). Apesar de a Área de Ciências da Saúde titular mais mulheres que homens, como observado anteriormente, a docência na área, em 2003, era de supremacia masculina (60,4\%). Nas grandes áreas de Engenharias e de Ciências Exatas e da Terra, as mulheres representavam menos de um quarto do total de docentes nesse ano. ${ }^{34}$

Além de a superação das mulheres na pós-graduação stricto sensu não se refletir no corpo docente universitário, outro fato de importante discussão é sua menor remuneração frente às mesmas funções executadas. Em 2008, as mulheres com título de mestrado obtidos no Brasil no período 1996-2009 receberam, em dezembro de 2009, remuneração média 28\% menor do que a dos homens que obtiveram título de mestrado no mesmo período. ${ }^{29}$ Em relação aos doutores do sexo feminino, a remuneração mensal média era $11 \%$ inferior à dos doutores do sexo masculino. Apesar de a média do número contratual de horas de trabalho e o tempo de emprego no principal vínculo empregatício dos homens serem relativamente superiores aos das mulheres, as diferenças nessas variáveis parecem ser pouco significativas para explicarem toda a diferença de remuneração média existente. ${ }^{30}$

Como visto, já existe uma participação representativa das mulheres nas ciências, que, no entanto, ainda não é ampla em algumas áreas e não é significativa nas posições de poder. Os salários mais baixos são apontados como um dos fatores de baixa integração das mulheres no universo da Ciência, assim como os preconceitos, o casamento e os filhos. ${ }^{35}$

A superação da rígida separação de papéis de gênero no matrimônio tradicional foi superada parcialmente pelas mulheres ao longo do século XX. Contudo, o maior acesso à educação formal e o ingresso ao mundo do trabalho não significaram abdicação das tarefas do "lar". A superposição de atividades dos espaços privado e profissional por parte das mulheres e o não compartilhamento das tarefas do espaço privado pelos homens significaram uma carga adicional de trabalho para as mulheres - o que chamamos popularmente de "dupla jornada de trabalho".

Na divisão sexual do trabalho, compete ainda à mulher o papel do cuidado, seja dos filhos pequenos, dos pais/sogros idosos, dos doentes da casa, da própria casa. Cabe à mulher, por exemplo, faltar ao trabalho ou a sua atividade de formação para gerir as situações de cuidado emergenciais. Nesta divisão, é também incumbência da mulher a manutenção da relação amorosa, denominada de “feminização do amor". A divisão sexual do trabalho é um dos obstáculos fundamentais presentes no percurso acadêmico das mulheres cientistas, dificultando o alcance de postos mais altos na carreira. ${ }^{36}$ 
As dificuldades enfrentadas por mulheres bolsistas de produtividade em pesquisa da área da Física, segundo a ótica das relações de gênero, em conciliar as exigências da carreira científica e as das relações amorosas e familiares, foram analisadas por Lima. ${ }^{36}$ Para as mulheres, muitas vezes, o investimento na carreira e nas relações afetivas são construídas como excludentes. Nos relatos, a maioria das pesquisadoras teve suas opções profissionais determinadas pelas escolhas profissionais dos parceiros e/ou maridos (doutorados inacabados, não realização de concursos...). Como se a carreira deles fosse a principal e a delas complementar ou secundária. Foram poucos os relatos em que o parceiro assumiu o ônus de ter uma carreira coadjuvante.

Outro dado encontrado foi o ofuscamento do mérito das mulheres nos casos de endogamia disciplinar, vista pelos pares como "alpinismo científico". As realizações das mulheres eram vistas com suspeitas quando em colaboração com seus cônjuges. Também foram citadas a concorrência entre os casais e a falta de apoio e incentivo à profissão. Reclamações ao levar trabalho para casa ou ao trabalhar no final de semana era comuns por parte da família. No entanto, quando o cônjuge estava nas condições citadas, isso não era um problema. A conciliação entre carreira e casamento e as decisões tomadas em função disso podem tornar as trajetórias profissionais lentas e tortuosas, dificultando o trabalho de acumulação de capital científico e reconhecimento acadêmico.

Ao observar os dados das bolsas de Produtividade em Pesquisa (PQ) e de pós-doutorado do Conselho Nacional de Desenvolvimento Científico e Tecnológico (CNPq) das carreiras consideradas mais femininas da Área de Ciências da Saúde (Fonoaudiologia, Enfermagem, Nutrição e Saúde Coletiva), observamos que as mulheres são maioria nas quatro áreas, mas o predomínio não é tão expressivo na Nutrição e na Saúde Coletiva. Nestas áreas também encontramos a minoria de mulheres em posições de maior prestígio, tais como nos níveis da bolsa PQ 1A (62\% destas bolsas foram concedidas a pesquisadores homens na Nutrição e a $68 \%$ na Saúde Coletiva). ${ }^{37}$

A bolsa é um indicativo de conhecimento e reconhecimento pelos próprios pares na carreira, como também é um importante capital científico ${ }^{38}$ que atrai mais capital simbólico e material. Os pesquisadores precisam acumular esse capital, pois é o que lhes proporciona autoridade para (re) definir as leis segundo as quais serão distribuídos os lucros no jogo, as leis que estabelecem se é ou não importante pesquisar e escrever sobre determinado tema. ${ }^{39}$ Os pesquisadores e suas linhas de pesquisa dominantes são aqueles que definem as intervenções científicas relevantes, as publicações, os temas, os objetos de estudo. Portanto, a autoridade e o poder no âmbito da Ciência na área de Nutrição estão sendo exercidos com maior expressão pelo sexo masculino.

Não estamos aqui reduzindo a questão de gênero a questões quantitativas, que nos remetem à quantidade inferior de mulheres que ocupam os mais altos postos de poder e prestígio, pois o sentido feminino pode estar presente em todos os espaços e práticas, mesmo quando esses postos são ocupados por pessoas do sexo masculino. Os números talvez traduzam os benefícios da divisão 
sexual do trabalho para os homens, tendo em vista que tais postos exigem maior produtividade, maior envolvimento laboral e dedicação temporal, o que pode significar abrir mão de uma vida familiar idealizada.

Parece-nos aqui importante refletir nutrição e gênero na literatura, sendo esta última categoria analítica central, como também fruto de um habitus ${ }^{40}$ que naturaliza a profissão do nutricionista como feminina. Estruturado socialmente, mas ao mesmo tempo estruturante das ações sociais, o habitus garante a interiorização de valores, crenças e normas (leis sociais), adequando o agente à sua posição social. ${ }^{38}$ Enfim, um modo de conceber e viver a profissão que leva a se dizer, no cotidiano, "é assim mesmo".

\section{Considerações finais}

Este ensaio pretendeu demonstrar, através de uma visita crítica e reflexiva sobre gênero e Nutrição, algumas faces desta questão nessa profissão predominantemente feminina. Embora a presença dos homens nos cursos de Nutrição tenha crescido nas últimas décadas, observa-se que eles buscam, prioritariamente, áreas de atuação associadas a atributos da identidade masculina, que valorizem a virilidade e a força física, como em academias ou clubes esportivos, enquanto as mulheres permanecem atuando principalmente na área da Nutrição Clínica ou nos restaurantes.

A possibilidade de exercer uma profissão e com isso obter certa autonomia e respeito foi uma importante mudança para as mulheres que possuíam a vida limitada ao trabalho doméstico. Por outro lado, a extensão desse trabalho doméstico à esfera profissional pode ter contribuído para a dificuldade inicial de se traçar a identidade profissional do nutricionista. Perceber que a profissão de nutricionista é permeada por significações de gênero na sua constituição histórica é fundamental para a compreendermos na contemporaneidade.

Os avanços alcançados pela categoria nas últimas décadas, destacando a ampliação dos campos de atuação, o reconhecimento profissional no meio acadêmico e no mercado de trabalho, demonstram conquistas sociais conseguidas pelas mulheres.

Destacamos que muitas são as ponderações que podem ser feitas acerca desta temática e muitas são as inquietações ainda existentes. Quais os motivos de escolha da profissão atualmente? Se a Nutrição no início se apresentava como uma especialização culturalmente mais apropriada à mulher e derivada de um trabalho doméstico e feminino, como podemos olhar para esta profissão hoje, depois de mais de 50 anos de sua primeira escola de nível superior? Quais as relações que podemos observar com as mudanças na carreira e a maior inserção da identidade masculina? Como avançaremos nas discussões que nos permitam tornar visíveis as transgêneros na construção da profissão? 
Apesar da persistência de assimetrias e da naturalização de sentidos estabelecidos nas relações sociais engendradas por homens e mulheres destacadas neste ensaio, é importante lembrar que estas relações e sentidos não são estanques. Os conflitos na condução da carreira, por exemplo, podem se delinear de outra forma, quando se considera o fato de que há nutricionistas casadas com mulheres. A despeito da predominância numérica de mulheres entre os nutricionistas, a profissão não é exclusivamente feminina, e o lento e recente ingresso das transgêneros certamente trará novos contornos às discussões colocadas.

Acreditamos que o texto retoma uma discussão importante à profissão do nutricionista, sua natureza dita como feminina, dando visibilidade a algumas questões relacionadas ao gênero no processo de organização social e fornecendo pontos de discussão para novas questões e novas perspectivas para esse campo de estudos.

\section{Referências}

1. Conselho Federal de Nutricionistas. Perfil da atuação profissional do nutricionista no Brasil. Brasília: CFN; 2006. 88 p.

2. L’Abbate S. As políticas de alimentação e nutrição no Brasil. v. I.: período de 1940 a 1964. Rev. Nutr. 1988; 1(2):87-138.

3. Vasconcelos FAG. O nutricionista no Brasil: uma análise histórica. Rev. Nutr. 2002; 15(2):127-138.

4. Summerfield P. Research on women in Britain in the second world war: an historiographical essay. Cahiers d'Histoire du Temps Présent 1998; 4:207-226.

5. Costa D. Experiência brasileira em restaurantes populares. Boletín de la Oficina Sanitaria Panamericana1947; 26(5):415-421.

6. Evangelista AMDC, Yazbeck DCDM. Serviço de Alimentação da Previdência Social (SAPS). Revista Virtú - ICH 2008; 7. [cesso em: 21 maio 2010]. Disponível em: http://www.ufjf.br/virtu/ files/2010/05/artigo-7a3.pdf

7. Bezerra JAB. O processo de gênese do saber em alimentação e nutrição: emergência, divulgação e aplicação social. XXV Simpósio Nacional de História; 2009; Fortaleza. Ceará: História e ética; 2009. p. 200-212.

8. Vasconcelos FAG, Calado CLA. Profissão nutricionista: 70 anos de história no Brasil. Rev. Nutr. 2011; 24(4):605-617.

9. Andrade LP, Lima ES. A formação e a prática do nutricionista: o gênero nas entrelinhas. Nutrire: Rev. Bras. Alim. Nutr. 2003; 26:109-126.

10. Nahes S. Revista FON-FON: a imagem da mulher no Estado Novo (1937-1945). Arte \& Ciência 2007. 168 p.

11. Associação Brasileira de Nutrição. São Paulo: ASBRAN; 2015. [acesso em: 05 abr. 2016]. Disponível em: http://www.asbran.org.br/numeros.php 
12. Instituto Nacional de Estudos e Pesquisas Educacionais Anísio Teixeira. Brasília: INEP; 2013. Disponível em: http://www.inep.gov.br/

13. Brasil. Resolução CNE/CES no 5, de 7 nov. 2001. Institui Diretrizes Curriculares Nacionais do Curso de Graduação em Nutrição. [acesso em: 04 abr. 2016]. Disponível em: http://portal.mec.gov.br/cne/ arquivos/pdf/CES05.pdf

14. Bourdieu P. Dominação masculina. 2 ed. Rio de Janeiro: Bertrand Brasil; 2002. 160 p.

15. Bruschini C, Lombardi MR. Médicas, arquitetas, advogadas e engenheiras: mulheres em carreiras profissionais de prestígio. Revista Estudos Feministas 1999; 7(1/2):9-24.

16. Bruschini C. O trabalho da mulher brasileira nas décadas recentes. Revista Estudos Feministas jan.1994; (número especial):179-199.

17. Bruschini MCA. Trabalho e gênero no Brasil nos últimos dez anos. Cadernos de Pesquisa 2007; 37(132):537-572.

18. Laqueur T. Inventando o sexo: corpo e gênero dos gregos a Freud. Rio de Janeiro: Relume Dumará; 2001. 374 p.

19. Whitaker D. Escolha da carreira e globalização. São Paulo: Moderna; 1988.96 p.

20. Lassance MCP, Magalhães MO. Gênero e escolha profissional. In: Levenfus RS, organizador. Psicodinâmica da escolha profissional. Porto Alegre: Artes Médicas; 1997. p. 47-61.

21. Cassiano J. Universidade para quem? Acesso e permanência de travestis e transexuais nas instituições de ensino superior. Circuito Acadêmico, UFRJ, IFCS; 07 nov. 2015. [acesso em: 09 ago. 2016]. Disponível em: https://circuitoacademico.com.br/2015/10/07/universidade-para-quem-acesso-e-apermanencia-de-travestis-e-transexuais-nas-instituicoes-de-ensino-superior/

22. Carneiro JD. 'Quero mostrar que é possível' diz travesti cotada a reitoria no Ceará. BBC Brasil 13 jan. 2015. [acesso em: 09 ago. 2016]. Disponível em: http://www.bbc.com/portuguese/ noticias/2015/01/150112_travesti_reitoria_ceara_jc_cc

23. Costa NMSC. Revisitando os estudos e eventos sobre a formação do nutricionista no Brasil. Rev. Nutr. 1999; 12(1):5-19.

24. Bosi MLM. Profissionalização e conhecimento: a nutrição em questão. São Paulo: Hucitec; 1996. 205 p.

25. Prado SD, Bosi MLM, Carvalho MCVS, Gugelmin SA, Silva JK, Delmaschio KL. A pesquisa sobre alimentação no Brasil: sustentando a autonomia do campo Alimentação e Nutrição. Ciênc. Saúde Coletiva 2011; 16(1):107-119.

26. Associação Brasileira de Nutrição. Histórico do nutricionista no Brasil, 1939-1989: coletânea de depoimentos e documentos. São Paulo: Atheneu; 1991. 442 p.

27. Viana SV. Nutrição, trabalho e sociedade: uma identidade profissional em conflito. São Paulo: Hucitec; Salvador: EDUFBA; 1996. 167 p.

28. Evangelista AMDC. Arroz e feijão, discos e livros: história e memórias do Serviço de Alimentação da Previdência Social, SAPS (1940-1967). Niterói: Universidade Federal Fluminense; 2012. 206 p. 
29. Centro de Gestão e Estudos Estratégicos. Mestres 2012: estudos da demografia da base técnicocientífica brasileira. Brasília: CGEE; 2012. 428 p. [acesso em: 10 maio 2013]. Disponível em: http:// www.cgee.org.br/publicacoes/mestres_e_doutores.php

30. Centro de Gestão e Estudos Estratégicos. Doutores 2010: estudos da demografia da base técnicocientífica brasileira. Brasília: CGEE; 2010. 508 p. [acesso em: 11 maio 2013]. Disponível em: http:// www.cgee.org.br/publicacoes/mestres_e_doutores.php

31. Souza LKCS, Prado SD, Ferreira FR, Carvalho MCVS. Eu queria aprender a ser docente: sobre a formação de mestres nos programas de pós-graduação do campo da Alimentação e Nutrição no Brasil. Rev. Nutr. 2014; 27(6):725-734.

32. Bourdieu P. O poder simbólico. Rio de Janeiro: Bertrand Brasil; 2011. 322 p.

33. Brasil. Ministério da Educação. Instituto Nacional de Estudos e Pesquisas Educacionais Anísio Teixeira. Censo da educação superior 2013: resumo técnico. Brasília: INEP/DEED; 2015. 80 p.

34. Godinho T, Ristoff D, Fontes A, Xavier IM, Sampaio CEM. Trajetória da mulher na educação brasileira: 1996-2003. Brasília: Instituto Nacional de Estudos e Pesquisas Educacionais Anísio Teixeira; 2006. 149 p.

35. Tabak F. O laboratório de Pandora: estudos sobre a ciência no feminino. Rio de Janeiro: Garamond; 2002. 267 p.

36. Lima BS. Quando o amor amarra: reflexões sobre as relações afetivas e a carreira científica. Gênero 2011; 12(1):9-21.

37. Conselho Nacional de Desenvolvimento Científico e Tecnológico. Bolsas. CNPq. [Acesso em: 14 abr. 2016]. Disponível em: http://cnpq.br/bolsistas-vigentes

38. Bourdieu P. O campo científico. In: Ortiz R, organizador. Sociologia. São Paulo: Ática; 1983. 191 p. Coleção grandes cientistas sociais, n. 39

39. Bourdieu P. Os usos sociais da ciência: por uma sociologia clínica do campo científico. São Paulo: Unesp; 2004. 88 p.

40. Bourdieu P. O senso prático. Petrópolis, RJ: Vozes; 2009. 471 p.

Recebido: 16/6/2016

Revisado: 03/8/2016

Aceito: 25/8/2016 